\title{
Correlates of partner and family violence among older Canadians: a life-course approach
}

\section{Miszkurka, PhD (1, 2); C. Steensma, MSc (1, 2); S. P. Phillips, MD (3)}

This article has been peer reviewed.

\section{Abstract}

Introduction: Knowledge about individual and interpersonal correlates of violence in Canadian seniors is limited. This study identifies correlates of current and past violence by intimate partner and family member(s) in community-dwelling Canadian seniors, while accounting for childhood adverse circumstances.

Methods: We performed logistic regression analysis of baseline data from a longitudinal study of community-dwelling individuals aged 65 to 74 years and living in Kingston (Ontario) and Saint-Hyacinthe (Quebec). Domestic violence was assessed using the HurtInsult-Threaten-Scream (HITS) screening tool. Odds ratios (ORs) are reported with $95 \%$ confidence intervals (CIs).

Results: Current violence of a psychological nature was reported by $18 \%$ of the sample. Women were at greater risk of current and lifetime violence perpetrated by a family member (current violence: adjusted OR $=1.83 ; 95 \% \mathrm{CI}: 1.02-3.30$ ) as well as experiencing violence from their intimate partner in their lifetime than were men (adjusted OR $=2.48 ; 95 \%$ CI: 1.40-4.37). Risk factors have accumulated over the life course that were found to be consistently associated with both current and lifetime violence included having witnessed violence at home in childhood (lifetime violence by family member: adjusted OR $=9.46$; $95 \% \mathrm{CI}$ : 5.11-17.52), as well as poor quality of relationships with intimate partners, family and friends.

Conclusion: Our research documents the ongoing impact of early adversity on subsequent partner and family violence in Canada. Findings identify some preventable factors associated with current psychological violence and past violence among communitydwelling Canadian seniors.

Keywords: Interpersonal violence, seniors, life course, adversity

\section{Introduction}

The World Health Organization definition of violence includes all types of physical and psychological abuse that present a substantial burden on individuals, families and communities. ${ }^{1}$ Common types of abuse include physical violence as well as neglect, verbal and financial abuse ${ }^{2}$ and, in the case of intimate partner violence, emotional abuse. $^{3}$ Older people constitute a susceptible group for partner and family violence. Approximately $7 \%$ of non-institutionalized older Canadian adults report some form of maltreatment. ${ }^{4}$ This violence has serious health consequences for older adults and is a public health issue for communities.

Interpersonal violence is both predicted by and has a negative impact on development, family relationships and support. ${ }^{5}$ Health- and age-related characteristics
Highlights

- Knowing what leads to elder abuse can help in developing programs that identify, prevent and minimize this violence. This will be increasingly important as the Canadian population ages.

- $9.6 \%$ of 65 - to 74-year-old seniors who lived in the community said a family member had been violent towards them in the last 6 months. $18 \%$ reported psychological violence by a partner in the same period of time (past 6 months).

- More women than men said that a partner or family member had been psychologically or physically violent towards them.

- People who witnessed violence at home when they were children or had poor relationships with their intimate partner or family or friends were more likely to experience short-term and long-term domestic violence.

- Preventive policies should aim at breaking the circle of violence in the earliest possible stages.

such as cognitive impairment, chronic disease and needing assistance with daily living activities are strong predictors of abuse as are interpersonal issues such as conflict with family and friends. ${ }^{6}$ Women are at greater risk of violence by a partner, and women with disabilities are at particular risk for severe violence. ${ }^{7}$

Exposure to violence early in life can contribute to subsequent poor health, alcohol dependence and conjugal violence. ${ }^{8}$ Similarly, experiences of violence across the lifespan are associated with

Author references:

1. Health Promotion and Chronic Disease Prevention Branch, Public Health Agency of Canada, Montreal, Quebec, Canada

2. Department of Social Science and Preventive Medicine, Université de Montréal, Montreal, Quebec, Canada

3. School of Medicine, Queen's University, Kingston, Ontario, Canada

Correspondence: Malgorzata Miszkurka, 200 boul. René-Levesque Ouest, Tour Est Bureau 1102, Montréal, QC H2Z 1X4; Tel: 514-283-4081; Fax: 514-496-7012;

Email: malgorata.goshia.miszkurka@phac-aspc.gc.ca 
poorer mental and physical well-being ${ }^{9}$ and can predict current victimization. ${ }^{10}$ However, few studies of elder abuse have taken a life-course approach that investigates early exposures to adversity and/or violence as predictors of violence in seniors. In addition, there is a dearth of original research on correlates of violence in older Canadian adults in general and on comparative analyses examining seniors' experiences of interpersonal violence by an intimate partner or family member in particular. Such information can help inform policies and interventions that prevent, identify and minimize elder abuse-which will be of increasing importance as the Canadian population ages.

Our study examines both individual (behavioural, health and socioeconomic) and interpersonal (partner/family relationships) correlates of lifetime and current physical and psychological violence experienced by older Canadians while also accounting for the long-term impact of childhood adversities.

\section{Methods}

We analyzed baseline data (2012) from the two Canadian sites of the International Mobility in Aging Study (IMIAS) of communitydwelling individuals aged 65 to 74 years old. Participants were recruited to the IMIAS study by letter from their family physician. Approximately $30 \%$ of those who received invitations contacted the research team in Kingston, Ontario ( $\mathrm{n}=398$ total, $\mathrm{n}=186$ men, $\mathrm{n}=212$ women) and Saint-Hyacinthe, Quebec ( $\mathrm{n}=$ 401 total, $\mathrm{n}=191$ men, $\mathrm{n}=210$ women), with a $95 \%$ rate of participation following that initial contact. Participants were excluded if they presented a higher risk for dementia on standardized testing. All modules embedded within the questionnaire were previously validated and translated from English to French. Interviewer training and protocol instructions were identical for both locations.

We obtained ethics approvals from Queen's University and the University of Montréal.

\section{Measures}

Outcome variable: We assessed domestic violence using the screening tool HurtInsult-Threaten-Scream (HITS), which had been previously validated in both female and male samples. ${ }^{11}$ Participants were asked if they ever or in the past six months had had a partner or family member who screamed at, insulted, threatened, cursed, talked down to or physically hurt them. Responses were summarized separately for current and lifetime physical and psychological violence according to the perpetrator (intimate partner or family member). For the present study, responses were dichotomized as follows: answers of "sometimes," "fairly often" and "frequently" were coded as "yes" for physical violence; for psychological violence, answers of "fairly often" and "frequently" were collapsed into the "yes" category. Four separate outcomes were subsequently defined: current psychological intimate partner violence; current psychological family member violence; and by combining lifetime physical and lifetime psychological violence for each, lifetime intimate partner violence and lifetime family member violence.

Individual characteristics. Sociodemographic characteristics included age, immigrant and marital status, sex, education, occupation, annual income and self-reported income sufficiency for basic needs. Two measures of health status were used: body mass index and the average cumulative number of key chronic conditions (high blood pressure, arthritis, osteoporosis, lung disease, cancer, heart disease, cerebrovascular disease or diabetes). An activities of daily living indicator identified those unable to independently bathe, dress, toilet hygiene, transfer, or feed. ${ }^{12}$ The Nagi questionnaire was used to quantify self-rated mobility limitation, ${ }^{13}$ while the number of falls in the previous 12 months was documented using the Falls Efficacy Scale International (FES-I). ${ }^{14}$ We assessed health behaviours using alcohol consumption, smoking and body mass index.

Interpersonal characteristics. IMIAS data included living arrangements (alone, only with partner, with children and/or partner and/or others). We created a social activities score based on the frequency of visits to community/recreation centres, seniors' associations, stores/malls or religious activities in the preceding 12 months, and quantified relationship quality based on satisfaction with relationships with friends and family. A partnership quality score summarized responses to questions about feeling loved and appreciated by, and listened to and important to one's intimate partner.

Life course adverse experiences. IMIAS assessed adverse experiences during the first 15 years of life based on the Survey on Health, Well-Being and Aging (SABE).${ }^{15}$ We included measures of childhood poverty, hunger, prolonged parental unemployment, witnessing violence at home, parental alcohol or drug abuse, and divorce.

\section{Statistical analyses}

The selection of potential factors associated with violence in seniors was guided by a social-ecological framework for violence prevention ${ }^{16}$ that considers the complex interplay between factors at the individual, relationship, community and societal level. The categorization of some variables may differ slightly across our constructed models as multiple categories were occasionally collapsed.

We used Student's $t$ test and chi-square testing to examine the differences in distribution between men and women for all individual, interpersonal and violence characteristics. To test the relevance of life-course experiences of violence, we cross-tabulated current and past violence to examine the portion of the sample that reported past and current violence. Collinearity testing between independent variables was performed using linear regression by requesting collinearity diagnostics for each multiple regression model. The model building consisted of four major steps. First, bivariate logistic regression analyses were performed to assess the associations between individual independent variables and each of the four violence outcomes. Variables that were associated with violence $(p<.05)$ were subsequently entered in multivariable models. Age as a covariate was assessed but was not included in any of the bivariate or multivariable models because it did not significantly influence any of the models and was of minimal interest in this study population due to the narrow age range. Three different multivariable logistic regression models were constructed for each of the four categories of violence. The first model included all significant individual and interpersonal characteristics. Variables for life-course experiences of violence were then progressively introduced into the second model, followed by indicators 
of childhood adverse circumstances in the third. To examine differences in men's and women's experiences of violence, interaction terms between sex and factors included in each model were tested for their statistical significance: we found no significant interactions. All models were adjusted for place of birth, annual income, education and occupation. P values under .05 were considered statistically significant. Odds ratios (ORs) and adjusted odds ratios (aORs) were calculated with $95 \%$ confidence intervals (CIs). Analyses were undertaken using SPSS version 21 (IBM, Chicago, IL, USA).

\section{Results}

Sex differences in Canadian IMIAS participants'characteristics and circumstances are shown in Table 1.

In total, $18 \%$ of participants reported violence by an intimate partner in the past six months (Table 2). There were no sex differences in reporting recent partner violence. However, women reported more lifetime psychological $(16.6 \%$ versus $10.3 \%, p<.01)$ and physical violence by a partner $(7.1 \%$ versus $0.8 \%, p<.0001)$ than did men. Psychological lifetime violence by a family member was more than twice as frequent among women than men (12.1\% versus $4.8 \%, p<.0001)$.

Tables 3 to 6 show the unadjusted and adjusted associations for each of the four violence experiences: current psychological violence by a partner, lifetime violence by a partner, current psychological violence by a family member, and lifetime violence by a family member.

\section{Current psychological violence by a partner}

Significant problems walking 400 metres, having had two or more falls in the previous 12 months, and drinking every day were strongly associated with psychological violence by a partner in the previous six months (see Table 3). Life-course experience of violence by an intimate partner and witnessing violence at home during childhood were also strongly associated with current psychological partner violence. On the other hand, living only with a partner/spouse rather than with children or others appeared to be protective, as was higher relationship quality.

In multivariable models, with the exception of falls, all of the correlates remained independently associated with the outcome. Life-course experience of violence by a partner and difficulties with walking were the strongest independent correlates of current psychological partner violence. Individuals who reported experiencing violence in their lifetime from an intimate partner were more than five times more likely to experience intimate partner violence of a psychological nature in the previous six months $(\mathrm{aOR}=5.29 ; 95 \% \mathrm{CI}: 2.71-10.33)$. Compared to those without mobility limitations, difficulty walking $400 \mathrm{~m}$ was associated with a five times higher likelihood of current partner violence (aOR $=5.00$; $95 \% \mathrm{CI}$ : $1.53-$ 16.29). Previous experience of intimate partner violence had only a small explanatory value with respect to the link between heavy alcohol consumption and current psychological partner violence. Inclusion of witnessing violence at home in childhood did not significantly change other associations but remained significant in and of itself.

\section{Lifetime violence by a partner}

Being female, daily alcohol consumption, obesity, living with children, problems with mobility or activities of daily living, falls, and early experiences of parental drug/ alcohol abuse and parental divorce were all individually associated with intimate partner violence across one's life, as was earlier abuse by a family member ( $\mathrm{OR}=4.16$; 95\% CI: 2.52-6.85) (Table 4).

In multivariable analyses, sex, daily alcohol consumption $(\mathrm{aOR}=6.83$; 95\% CI: 2.30 20.23), obesity, and early experiences of violence by a family member or parental divorce remained independently associated with lifetime violence by a partner. Experiencing lifetime violence by a family member appeared to partially explain the association between daily alcohol use and lifetime partner violence (see difference between multivariable models 1 and 2). Adverse childhood experiences (parental divorce or drinking/drug use) also partially explained the association between earlier violence by a family member and lifetime partner violence (see difference between multivariable models 2 and 3).
Current psychological violence by a family member

Individual correlates of psychological violence in the previous six months by a family member included being female, selfperceived insufficient income, living with a child, poor relationships with family members and/or friends, and witnessing physical violence between family members in childhood (Table 5). Lifetime violence also increased the likelihood of current psychological violence by a family member $(\mathrm{OR}=2.68$; $95 \% \mathrm{CI}: 1.54-4.61)$. The association between living with a child/others and the outcome was substantially reduced in a multivariable model adjusted for individual/interpersonal characteristics (model 1) and was no longer significant in the final model. The inclusion of past violence and adverse childhood circumstances did not change associations between current characteristics and the outcome.

\section{Lifetime violence by a family member}

Being female, being widowed or separated/ divorced, self-perceived insufficient income, problems with mobility or activities of daily living, and smoking each increased the likelihood of violence across the lifespan by a family member, as did low quality and quantity of relationships (Table 6). Early circumstances such as hunger, parental divorce, parental substance abuse, and witnessing violence at home were strong predictors of lifetime violence by family members. In the multivariable model including all current characteristics (model 1), being female and having few friends, poor relationships with family and friends, and limitations in activities of daily living were each independently associated with lifetime violence by a family member. Similarly, lifetime experience of violence by a partner was strongly linked to lifetime violence by family members (aOR $=3.58 ; 95 \%$ CI: 1.88-6.83). Witnessing physical violence at home during childhood remained the strongest factor associated with lifetime violence by a family member $(\mathrm{aOR}=9.46$; 95\% CI: 5.11-17.52).

\section{Discussion}

In this Canadian study of communitydwelling seniors we report on individual 
TABLE 1

Distribution of individual and interpersonal characteristics by sex

\begin{tabular}{|c|c|c|c|c|}
\hline \multirow[t]{2}{*}{ Characteristic } & \multicolumn{3}{|c|}{ Percentage (n) } & \multirow{2}{*}{$p$ value } \\
\hline & Total $(n=799)$ & Men $(n=377)$ & Women $(n=422)$ & \\
\hline \multicolumn{5}{|l|}{ Individual } \\
\hline Single (never married) & $4.6 \%(37)$ & $3.2 \%(12)$ & $5.9 \%(25)$ & .000 \\
\hline Married/common law & $66.1 \%(528)$ & $77.5 \%(292)$ & $55.9 \%(236)$ & \\
\hline Widow/widower & $10.6 \%(85)$ & $4.2 \%(16)$ & $16.4 \%(69)$ & \\
\hline \multicolumn{5}{|l|}{ Perceived income } \\
\hline Insufficient & $6.4 \%(51)$ & $4.0 \%(15)$ & $8.5 \%(36)$ & .009 \\
\hline Suitable & $41.1 \%(328)$ & $39.3 \%(148)$ & $42.7 \%(180)$ & \\
\hline Sufficient & $52.6 \%(420)$ & $56.8 \%(214)$ & $48.8 \%(206)$ & \\
\hline Chronic diseases (mean number) & 1.79 & 1.65 & 1.92 & .004 \\
\hline \multicolumn{5}{|l|}{ Alcohol consumption } \\
\hline None & $22.2 \%(177)$ & $16.8 \%(63)$ & $27.1 \%(114)$ & .000 \\
\hline Less than weekly & $29.4 \%(234)$ & $24.5 \%(92)$ & $33.6 \%(142)$ & \\
\hline Weekly & $45.3 \%(361)$ & $53.5 \%(201)$ & $38.0 \%(160)$ & \\
\hline Daily & $3.1 \%(25)$ & $5.3 \%(20)$ & $1.2 \%(5)$ & \\
\hline Severity of drinking (mean number of drinks/sitting) & 3.58 & 4.08 & 3.13 & .000 \\
\hline Current Smoking & $7.3 \%(58)$ & $7.7 \%(29)$ & $6.9 \%(29)$ & .661 \\
\hline \multicolumn{5}{|l|}{ Body Mass Index } \\
\hline Underweight & $2.8 \%(22)$ & $1.3 \%(5)$ & $4.0 \%(17)$ & .016 \\
\hline \multicolumn{5}{|l|}{ Adverse childhood circumstances } \\
\hline Parents out of work & $8.4 \%(67)$ & $9.3 \%(35)$ & $7.6 \%(32)$ & .443 \\
\hline Parental divorce & $3.4 \%(27)$ & $3.2 \%(12)$ & $3.6 \%(15)$ & .846 \\
\hline Parental substance abuse & $14.6 \%(117)$ & $13.0 \%(49)$ & $16.1 \%(68)$ & .230 \\
\hline Witnessed violence at home & $13.5 \%(108)$ & $9.3 \%(35)$ & $17.3 \%(73)$ & .001 \\
\hline \multicolumn{5}{|l|}{ Interpersonal } \\
\hline \multicolumn{5}{|l|}{ Living situation } \\
\hline Living alone & $28.9 \%(231)$ & $17.5 \%(66)$ & $39.1 \%(165)$ & .000 \\
\hline With spouse & $55.4 \%(443)$ & $58.9 \%(222)$ & $52.4 \%(221)$ & \\
\hline With spouse \& child & $12.5 \%(100)$ & $21.5 \%(81)$ & $4.5 \%(19)$ & \\
\hline With child & $1.8 \%(14)$ & $0.5 \%(2)$ & $2.8 \%(12)$ & \\
\hline With others & $1.4 \%(11)$ & $1.6 \%(6)$ & $1.2 \%(5)$ & \\
\hline Interpersonal relations (mean) & 12.06 & 12.28 & 11.90 & .039 \\
\hline Partnership quality score (mean) & 17.73 & 18.05 & 17.33 & .006 \\
\hline Social activities score (mean) & 5.18 & 4.99 & 5.35 & .035 \\
\hline
\end{tabular}


TABLE 2

Current and lifetime physical and psychological violence distribution according to sex

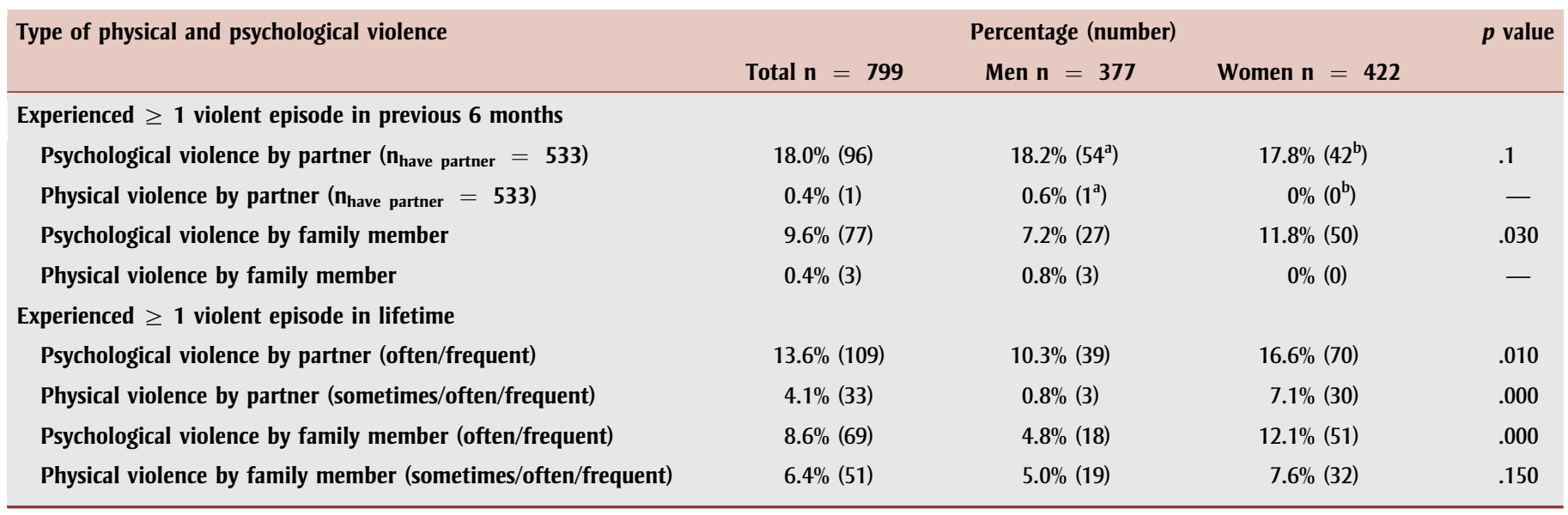

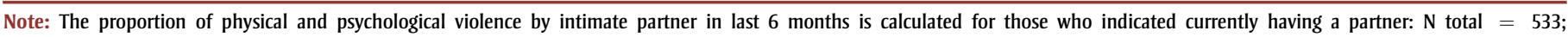
$\mathrm{N}$ men $^{\mathrm{a}}=297 ; \mathrm{N}$ woman $^{\mathrm{b}}=236$.

and interpersonal correlates of violence using a life-course approach. To the best of our knowledge, this is the first study to use a wide range of indicators of early adversity to assess correlates of elder abuse. Our results help identify potentially modifiable risk factors for violence. Our violence frequency estimates suggest that significant numbers of people who experienced physical and psychological violence in the past continue to be at risk into old age. Our rates of violence were similar to those reported in the literature, ${ }^{6}$ with psychological violence being more common than physical. Also, lifetime violence by a family member was more prevalent than lifetime violence by a partner, whereas current violence by a partner was higher than current violence by a family member.

We identified several factors that were consistently associated with both current psychological violence and lifetime violence along with a number of factors associated with either one or the other. With the exception of current psychological violence by a partner, women were at greater risk than men in our study, findings comparable to other studies that found women to be at greater risk for all types of abuse $\mathrm{e}^{17}$ as well as verbal and physical abuse. ${ }^{18,19}$ While two studies found men to have a higher risk for abuse $^{20,21}$ and another found no difference by $\operatorname{sex}^{22}$ it is difficult to interpret these results as one study ${ }^{20}$ did not control for potentially confounding factors such as living situation and health status and the other study $^{22}$ may have been unable to detect an effect due to the small proportion of men in the study population. Interestingly, of the outcomes we studied, the one where being female was not associated with risk was current psychological partner violence. Perhaps this is because conflictual relationships are increasingly resolved through divorce/ separation or death as we age. It has also been hypothesized that certain risks associated with current intimate partner violence are either sex-neutral or more common among men (e.g. stress related to cohabitation of caregiver and victim, social isolation, substance abuse in perpetrator, mental or physical impairments). ${ }^{23}$

TABLE 3

Odds ratios for bivariate and multivariable models for personal and interpersonal factors correlated with current psychological violence by intimate partner

\begin{tabular}{|c|c|c|c|c|}
\hline & \multicolumn{4}{|c|}{ Odds ratio (95\% Confidence interval) } \\
\hline & $\begin{array}{c}\text { Bivariate } \\
\text { (Unadjusted models) }\end{array}$ & $\begin{array}{c}\text { Adjusted multivariable } \\
\text { model } 1\end{array}$ & $\begin{array}{c}\text { Adjusted multivariable } \\
\text { model } 2\end{array}$ & $\begin{array}{c}\text { Adjusted multivariable } \\
\text { model } 3\end{array}$ \\
\hline Partnership quality & $0.88 * *(0.83-0.94)$ & $0.83 * *(0.77-0.90)$ & $0.84^{* *}(0.77-0.91)$ & $0.84 * *(0.78-0.91)$ \\
\hline Daily alcohol consumption & $2.35 *(1.13-4.88)$ & $2.65 *(1.14-6.20)$ & $2.63 *(1.10-6.31)$ & $2.25 * *(1.07-6.15)$ \\
\hline Problems walking $400 \mathrm{~m}$ & $4.13^{* *}(1.46-11.7)$ & $5.45 * *(1.81-16.38)$ & $5.01 * *(1.56-16.09)$ & $5.00 * *(1.53-16.29)$ \\
\hline Lifetime violence by partner & $5.87 * *(3.22-10.70)$ & & $5.36 * *(2.76-10.38)$ & $5.29 * *(2.71-10.33)$ \\
\hline Witnessed violence at home as a child & $2.06 *(1.13-3.75)$ & & & $2.10 *(1.06-4.17)$ \\
\hline
\end{tabular}

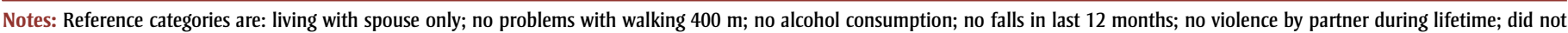

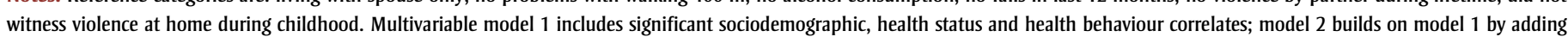

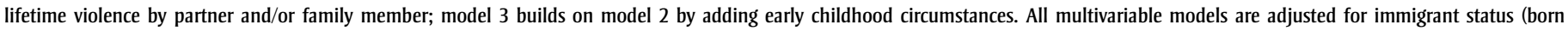
outside of Canada), education, occupation and income.

$* p<.05 ; * p<.01$. 
TABLE 4

Odds ratios for bivariate and multivariable models for personal and interpersonal factors correlated with lifetime violence by intimate partner

\begin{tabular}{|c|c|c|c|c|}
\hline & \multicolumn{4}{|c|}{ Odds ratio ( $95 \%$ confidence intervals) } \\
\hline & $\begin{array}{c}\text { Bivariate } \\
\text { (Unadjusted models) }\end{array}$ & $\begin{array}{l}\text { Adjusted multivariable } \\
\text { model } 1\end{array}$ & $\begin{array}{c}\text { Adjusted multivariable } \\
\text { model } 2\end{array}$ & $\begin{array}{c}\text { Adjusted multivariable } \\
\text { model } 3\end{array}$ \\
\hline Woman & $1.67 *(1.10-2.54)$ & $2.61 * *(1.49-4.53)$ & $2.42^{* *}(1.38-4.25)$ & $2.48 * *(1.40-4.37)$ \\
\hline Living with child & $3.81 *(1.28-11.39)$ & $2.17 *(1.13-4.18)$ & $1.92(0.99-3.75)$ & $1.85(0.95-3.63)$ \\
\hline Problems walking 400 m & $6.57 * *(1.86-23.13)$ & $0.70(0.27-1.13)$ & $0.67(0.22-2.02)$ & $0.70(0.23-2.09)$ \\
\hline At least one ADL limitation & $3.08 * *(1.58-6.01)$ & $2.72 *(1.12-6.62)$ & $2.30(0.92-.5 .75)$ & $2.14(0.85-5.39)$ \\
\hline Two or more falls & $2.51 *(1.17-5.38)$ & $1.38(0.74-2.57)$ & $1.40(0.75-2.64)$ & $1.40(0.74-2.65)$ \\
\hline Daily alcohol consumption & $4.70 * *(1.88-11.74)$ & $7.02 * *(2.43-20.29)$ & $6.53 * *(2.21-19.26)$ & $6.83 * *(2.30-20.23)$ \\
\hline BMI obese & $2.16 * *(1.23-3.80)$ & $2.25 * *(1.27-4.00)$ & $2.26 * *(1.97-6.40)$ & $2.22 * *(1.23-4.00)$ \\
\hline Lifetime violence by family member & $4.16 * *(2.52-6.85)$ & & $3.55^{* *}(1.97-6.40)$ & $3.07 * *(1.66-5.67)$ \\
\hline Parental substance abuse & $2.16 * *(1.33-3.52)$ & & & $1.48(0.82-2.67)$ \\
\hline Parental divorce in childhood & $3.32 * *(1.45-7.59)$ & & & $2.79 *(1.06-7.31)$ \\
\hline
\end{tabular}

Abbreviations: ADL, activity of daily living; BMI, body mass index.

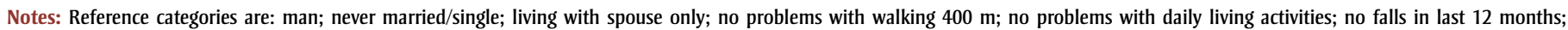
no alcohol consumption; normal BMI; no violence by family member during lifetime; did not witness parents abusing alcohol or drugs; parents did not divorce during childhood.

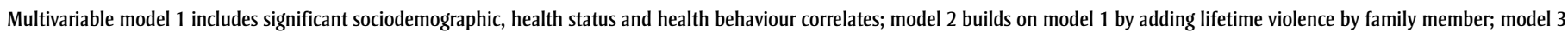
builds on model 2 by adding early childhood circumstances. All multivariable models are adjusted for immigrant status (born outside of Canada), education, occupation and income.

$* p<.05 ; * p<.01$.

Several factors were consistently associated with both current psychological violence and lifetime violence. The older people in our study were at greater risk of experiencing a physical or psychological violent episode involving a family member if they had a previous experience of violence involving their intimate partner, had witnessed violence between family members in childhood, and had poor quality relationships with family and friends. These risks for family-related violence were present regardless of whether the violent episode was experienced in the previous six months or within one's lifetime. With respect to partner-related violence, daily alcohol consumption was the only consistent factor associated with both current and lifetime violent episodes of this nature. However, previous experience of violence was also a common factor, as previous partner-related violence was associated with current partnerrelated violence, while previous family-related violence was associated with lifetime partnerrelated violence.
We also found that creating and maintaining close relationships throughout the life course was associated with less intimatepartner and family violence.

To our knowledge, this is the first study to address the role of the quality of the intimate partner relationship in elder abuse. Several small studies of older caregivers that did not differentiate between types of caregiver (i.e. intimate partner or other), found that those engaging in verbal abuse

TABLE 5

Odds ratios and $95 \% \mathrm{Cl}$ for bivariate and multivariable models for personal and interpersonal factors correlated with current psychological violence by family member

\begin{tabular}{|c|c|c|c|c|}
\hline & \multicolumn{4}{|c|}{ Odds ratio ( $95 \%$ confidence intervals) } \\
\hline & $\begin{array}{c}\text { Bivariate } \\
\text { (Unadjusted models) }\end{array}$ & $\begin{array}{c}\text { Adjusted multivariable } \\
\text { model } 1\end{array}$ & $\begin{array}{c}\text { Adjusted multivariable } \\
\text { model } 2\end{array}$ & $\begin{array}{c}\text { Adjusted multivariable } \\
\text { model } 3\end{array}$ \\
\hline Perceived insufficient income & $2.76 * *(1.31-5.83)$ & $2.30(0.97-5.48)$ & $2.16(0.90-5.18)$ & $2.17(0.90-5.24)$ \\
\hline Living with child or others & $4.79 * *(1.48-15.47)$ & $2.04 *(1.06-3.92)$ & $1.88(0.97-3.64)$ & $1.80(0.92-3.50)$ \\
\hline Poor quality relationships & $2.11 * *(1.30-3.42)$ & $2.06 * *(1.24-3.42)$ & $2.01 * *(1.21-3.36)$ & $1.95 *(1.16-3.26)$ \\
\hline Witnessed violence at home as a child & $2.33 * *(1.33-4.09)$ & & & $2.20 *(1.19-4.07)$ \\
\hline
\end{tabular}

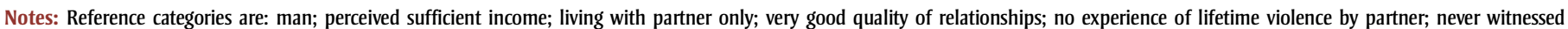

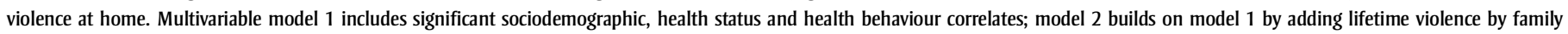

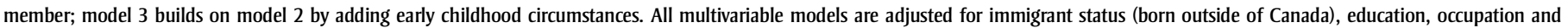
income.

$* p<.05 ; * * p<.01$ 
TABLE 6

Odds ratios and $95 \% \mathrm{Cl}$ for bivariate and multivariable models for personal and interpersonal factors correlated with lifetime violence by family member

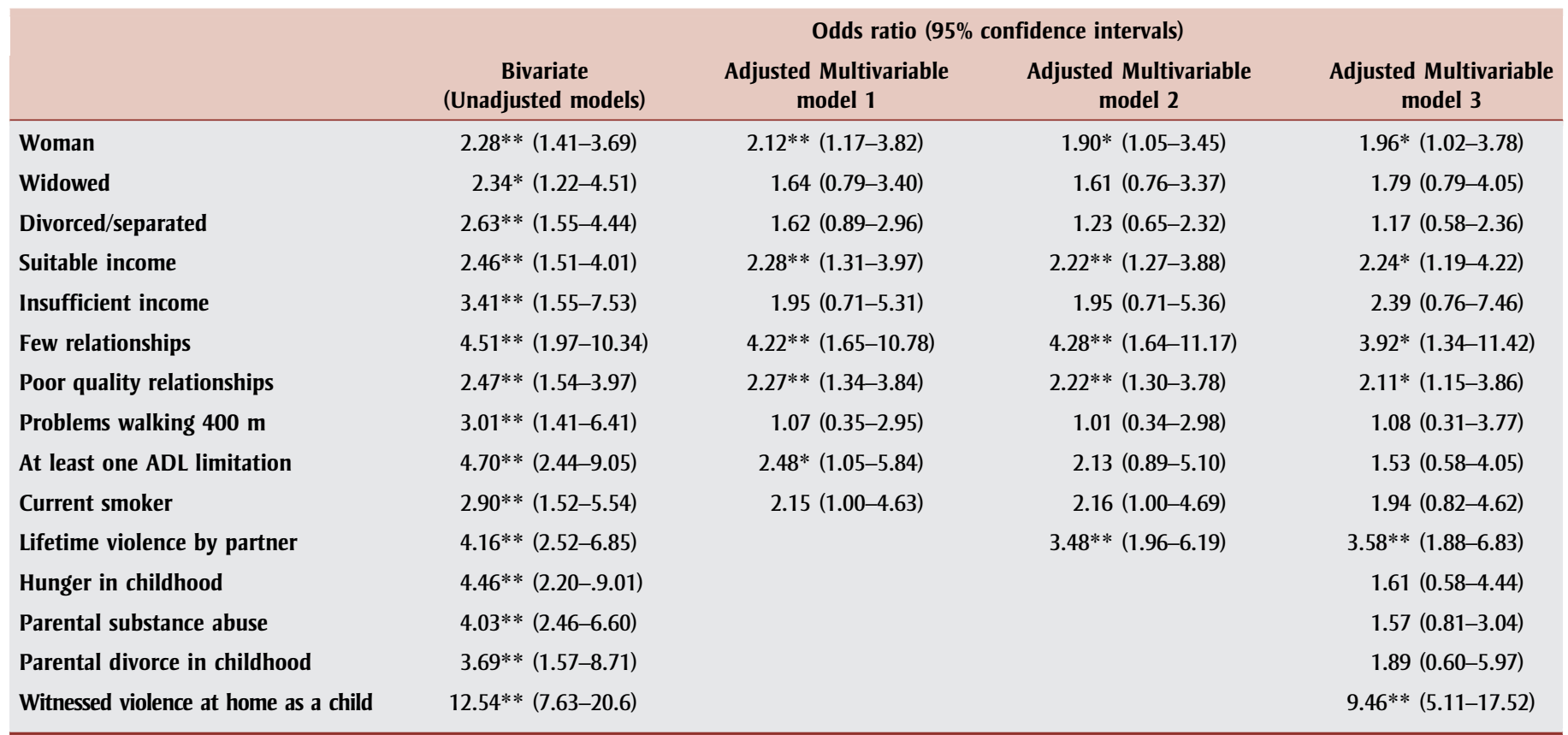

Abbreviation: ADL, activity of daily.

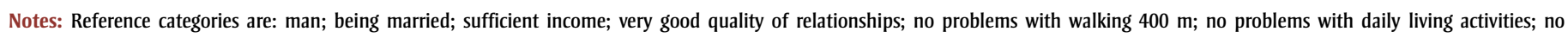
experience of lifetime violence by partner; no hunger in childhood; no parental divorce; did not witness parents abusing alcohol or drugs; never witnessed violence at home.

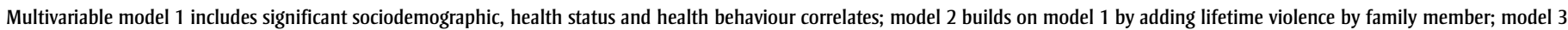
builds on model 2 by adding early childhood circumstances. All multivariable models are adjusted for immigrant status (born outside of Canada), education, occupation and income.

$* p<.05 ; * p<.01$.

were more likely to report a poor relationship with the victim prior to disability than those not engaging in abuse. ${ }^{24}$ Partnership quality in our study was determined by questions that addressed issues of perceived respect, appreciation and understanding by the intimate partner, and was among the strongest correlates of current violence by a partner. This is consistent with other studies that demonstrated large increases in risk for physical, psychological and overall abuse when the older person reports frequent arguing or poor relations with their family. ${ }^{6,17,21}$ This result underlined that interpersonal relations between partners remain a central factor of concern when addressing and tackling violence between partners, especially considering this association was independent of individual behaviour and health-related functional status.

Our results demonstrate the importance of the life course in explaining correlates of partner and family violence among older Canadians. In fact, previous experience of violence and adverse circumstance in childhood appeared as the strongest independent correlates of current psychological violence in elder adults. Two other Canadian studies that addressed elder abuse using a lifecourse perspective found that previous experiences of violence significantly increased risk for present abuse. A study of those aged 55 years and older reported that those who were abused before the age of 18 had a greater risk of abuse in older adulthood, independent of all other factors. ${ }^{22}$ Similarly, a more representative sample of household-dwelling Canadians aged 65 to 80 years found that those reporting an incident of sexual assault prior to the age of 60 were at greatest risk for recent physical assault. ${ }^{7}$ Existing research indicates that, for women in particular, childhood victimization influences future intimate relationships and increases the likelihood of victimization. ${ }^{25}$ As significant numbers of older people are now experiencing or have experienced violence perpetuated by their family and/or partner, preventive efforts and policies should aim at breaking the circle of violence in the earliest possible stages.

Our study is one of the first to document the ongoing impact of early adversity on subsequent partner and family violence in older Canadians. In our cohort, those whose parents divorced during the victim's childhood were almost three times more likely to report lifetime violence by their partner, suggesting that early family disruption is a marker of childhood adversity and one with lifelong effects. In addition, although not significant when controlling for other factors, parental alcohol or drug abuse during the victim's childhood also seemed to have a subsequent impact, increasing the risk of exposure to both partner and family lifetime violence. Of particular note, witnessing violence between family members early in life was the strongest predictor of ongoing family violence in later adulthood. Other studies not specific to older populations appear to 
reinforce this, reporting that childhood physical abuse or witnessing inter-parental violence are strongly and independently associated with recent intimate partner physical and emotional abuse. ${ }^{26}$ Our findings are in keeping with a growing literature describing how adversity during childhood has an incremental, long-lasting and harmful impact on many aspects of adult physical and mental well-being. ${ }^{27}$

Our study also identified a number of other independent correlates of lifetime violence and current psychological violence, including living arrangements and having poorer health/functional status. Living with spouse and children and/or other cohabitants constituted an independent correlate of partner violence, suggesting tensions related to shared living space as well as economic dependence of older adults on others. In fact, marital, family/child and health stress were among the most cited stressors perceived as causes of aggression between partners. ${ }^{28}$ In addition, functional problems such as falls (more than twice in last 12 months) and mobility issues (difficulty walking 400 metres) were strong correlates of current partner violence. These results suggest that the additional stresses related to incapacities arising as part of aging may add strain to a relationship. The literature supports these findings: individuals with disabilities, including older adults, are generally more at risk of victimization than are ablebodied persons. Thus seniors with disabilities or those needing assistance with daily living activities may be especially vulnerable to victimization at the hands of caregivers, in this case their current partners. ${ }^{29}$ The connection between functional status and violence may mean that the stresses inherent in incapacity can translate into intimate partner violence. Finding ways to alleviate caregiver strain might therefore have a beneficial effect and reduce risk of violence.

\section{Limitations}

Sampling methods may have contributed to the presence of mild to moderate selection biases in the study, resulting in our under- or over-estimating the degree of association between some variables and violence outcomes. The study sample was a voluntary one and may not be representative of the population of communitydwelling older adults with respect to the variables measured. For example, exclusion criteria based on cognitive health status meant that more severely disabled older adults did not participate in the study. With regard to potential nonresponse bias, we believe that response rates in our study were higher in more educated individuals. Should violence be reported more frequently in individuals who are less educated, such differences in response rates would have biased our estimates. Retrospective reports of lifetime violence and adverse childhood experiences could also be subject to recall bias, although the exclusion of those at risk for dementia should minimize this. Social desirability leading to underreporting of violence cannot be excluded due to the real possibility that participants may not want to reveal negative behaviours of their partner or family members. Combining physical and psychological interpersonal violence was necessary in our study in order to increase the number of events for each of the outcomes. A recent systematic review suggests that, independent of type of violence (psychological, physical, sexual, financial, neglect), many risk factors are common to psychological and physical violence. ${ }^{30}$ However, future studies should carefully examine the possible differences in violence correlates that are specific to each type of interpersonal violence. The low absolute prevalence of physical violence also suggests caution when interpreting results related to this experience.

In addition, because of the limited power of the study, we were unable to report on the effect of interactions between study correlates on the estimated association measures. Other key factors not addressed in this study include dependency of the victim on the perpetrator (or vice versa), characteristics of the perpetrator (e.g. mental health, stress related to care burden) as well as other personal and sociocultural characteristics. ${ }^{31}$

\section{Conclusions}

Very little Canadian research has specifically addressed interpersonal violence among older adults. We included an extensive list of possible individual and interpersonal correlates of interpersonal violence, and identified the most persistent associations with current and past self-reported violence in Canadian community-dwelling older adults. Identifying individual and interpersonal level factors could inform strategies for preventing current psychological violence such as those designed to promote attitudes, beliefs and behaviours aimed at reducing conflicts and fostering problem solving skills. ${ }^{16}$ Some older adults experienced lifetime violence both by a partner and a family member, revealing trajectories of cumulative violence. As Johannesen and LoGiudice ${ }^{32}$ suggested, the connections between types of violence at different stages of the life course and different patterns of abuse must be identified and better understood in order to develop appropriate prevention programs and interventions for children, women and families.

\section{Acknowledgements}

The authors would like to thank the following from Public Health Agency of Canada for their technical assistance and contributions to the study concept: Simone Powell, Seniors' Policy manager; Pamela Ponic, senior analyst, Injury Prevention Unit; Suzanne Hindmarch, Policy Planning and Intergovernmental Affairs Unit manager; and the Ontario region. Funding for this research was provided by the Canadian Institutes of Health Research. We would like to thank all study participants for their time and continuing involvement in this research.

\section{References}

1. Krug EG, Mercy JA, Dahlberg LL, Zwi AB. The world report on violence and health. Lancet. 2002;360(9339):1083-8.

2. Pittaway E, Westhues A. The prevalence of elder abuse and neglect of older adults who accessed health and social services in London, Ontario, Canada. J Elder Abuse Negl. 1993; 5(4):77-93.

3. Poole C, Rietschlin J. Intimate partner victimization among adults aged 60 and older: an analysis of the 1999 and 2004 General Social Survey. J Elder Abuse Negl. 2012; 24(2):120-37. 
4. Dauvergne M. Family violence against older adults. In: Statistics Canada, Canadian Centre for Justice Statistics, editor. Family violence in Canada: a statistical profile 2002, Ottawa (ON): Statistics Canada; 2002. p. 26-33 [Statistics Canada, Catalogue No.: 85-224-XIE.].

5. Grauerholz L. An ecological approach to understanding sexual revictimization: linking personal, interpersonal, and sociocultural factors and processes. Child Maltreat. 2000; 5(1):5-17.

6. Acierno R, Hernandez MA, Amstadter $A B$, et al. Prevalence and correlates of emotional, physical, sexual, and financial abuse and potential neglect in the United States: the National Elder Mistreatment Study. Am J Public Health. 2010;100(2):292-7.

7. Brozowski K, Hall DR. Aging and risk: physical and sexual abuse of elders in Canada. J Interpers Violence. 2010;25(7):1183-99.

8. Roustit C, Renahy E, Guernec G, Lesieur S, Parizot I, Chauvin P. Exposure to interparental violence and psychosocial maladjustment in the adult life course: advocacy for early prevention. J Epidemiol Community Health. 2009;63(7):563-8.

9. Bonomi AE, Thompson RS, Anderson M, et al. Intimate partner violence and women's physical, mental, and social functioning. Am J Prev Med. 2006;30(6):458-66.

10. Walsh CA, Ploeg J, Lohfeld L, Horne J, MacMillan H, Lai D. Violence across the lifespan: interconnections among forms of abuse as described by marginalized Canadian elders and their care-givers. Brit J Soc Work. 2007;37(3):491-514.

11. Bardwell J, Sherin K, Sinacore JM, Zitter R, Shakil A. Screening for domestic violence in family medicine. J Advocate Health Care. 1999;1(1):5-7.

12. Pluijm SM, Bardage C, Nikula S, et al. A harmonized measure of activities of daily living was a reliable and valid instrument for comparing disability in older people across countries. J Clin Epidemiol. 2005; 58(10):1015-23.

13. Nagi SZ. An epidemiology of disability among adults in the United States. Milbank Mem Fund Q Health Soc. 1976;54(4):439-67.
14. Delbaere K, Close JC, Mikolaizak AS, Sachdev PS, Brodaty H, Lord SR. The Falls Efficacy Scale International (FES-I). A comprehensive longitudinal validation study. Age Ageing. 2010;39(2):210-6.

15. Alvarado BE, Zunzunegui $\mathrm{M}$, Béland $\mathrm{F}$, Bamvita J. Life course social and health conditions linked to frailty in Latin American older men and women. J Gerontol A Biol Sci Med Sci. 2008;63(12):1399-406.

16. Centers for Disease Control and Prevention. The social-ecological model: a framework for prevention [Internet]. Atlanta (GA): National Center for Injury Prevention and Control; [cited 2013 Jul 17] Available at: http://www.cdc.gov/violenceprevention/ overview/social-ecologicalmodel.html

17. Pérez-Cárceles MD, Rubio L, Pereniguez JE, Pérez-Flores D, Osuna E, Luna A. Suspicion of elder abuse in South Eastern Spain: the extent and risk factors. Arch Gerontol Geriatr. 2009;49(1):132-7.

18. Chokkanathan S, Lee AE. Elder mistreatment in urban India: a community based study. J Elder Abuse Neglect. 2006;17(2):45-61.

19. Laumann EO, Leitsch SA, Waite LJ. Elder mistreatment in the United States: prevalence estimates from a nationally representative study. J Gerontol B Psycholl Sci Soc Sci. 2008;63(4):S248-54.

20. Pillemer K, Finkelhor D. The prevalence of elder abuse: a random sample survey. Gerontologist. 1988;28(1):51-7.

21. Oh J, Kim HS, Martins D, Kim H. A study of elder abuse in Korea. Int $\mathrm{J}$ Nurs Stud. 2006;43(2):203-14.

22. McDonald L, Thomas C. Elder abuse through a life course lens. Int Psychogeriatr. 2013;25(8):1235-43.

23. Reeves KA, Desmarais SL, Nicholls TL, Douglas KS. Intimate partner abuse of older men: considerations for the assessment of risk. J Elder Abuse Negl. 2007;19(1-2):7-27.

24. Compton S, Flanagan P, Gregg W. Elder abuse in people with dementia in Northern Ireland: prevalence and predictors in cases referred to a psychiatry of old age service. Int J Geriatr Psychiatry. 1997;12(6):632-5.
25. Carbone-López KC. In, out, and in again? A life course understanding of women's violent relationships. 2013; Unpublished doctoral dissertation, department of sociology, University of Minnesota, Twin Cities, MN. Document no: 240918:204 p.

26. Bensley L, Van Eenwyk J, Wynkoop Simmons K. Childhood family violence history and women's risk for intimate partner violence and poor health. Am J Prev Med. 2003;25(1):38-44.

27. Felitti M, Vincent J, Anda M, et al. Relationship of childhood abuse and household dysfunction to many of the leading causes of death in adults. The Adverse Childhood Experiences (ACE) Study. Am J Prev Med. 1998;14(4):245-58.

28. Flynn A, Graham K. "Why did it happen?". A review and conceptual framework for research on perpetrators' and victims' explanations for intimate partner violence. Aggress Violent Behav. 2010;15(3):239-51.

29. Amstadter AB, Zajac $K$, Strachan $M$, Hernandez MA, Kilpatrick DG, Acierno R. Prevalence and correlates of elder mistreatment in South Carolina: the South Carolina Elder Mistreatment Study. J Interpers Violence. 2011;26(15):2947-72.

30. National Research Council. Elder mistreatment: abuse, neglect, and exploitation in an aging America. Washington (DC): The National Academies Press; 2003.

31. Williams LM. Understanding child abuse and violence against women: a life course perspective. J Interpers Violence. 2003;18(4):441-51.

32. Johannesen M, LoGiudice D. Elder abuse: a systematic review of risk factors in communitydwelling elders. Age Aging. 2013;42:292-8. 